\title{
DERECHOEIECTORAL
}

PRIMER SEMESTRE 2020 NÚMERO 29

ISSN: 1659-2069

\section{¿Una crisis de la representación política? ${ }^{1}$}

Marie-Anne Cohendet*

https/doi/org/10.35242/RDE_2020_29_8

Nota del Consejo Editorial

Recepción: 7 de octubre de 2019.

Revisión, corrección y aprobación: 11 de noviembre de 2019.

Resumen: Analiza la situación actual de la democracia representativa que pareciera estar en crisis. Señala que, a pesar de la falta de credibilidad o reproches a las instituciones políticas producto de la corrupción, la crisis económica, la globalización, el retorno al discurso religioso y la crisis de identidad, aunada a la incapacidad de los políticos para cumplir o satisfacer las demandas de la población, la crisis se acentúa en dos ejes: falta de crecimiento de la democracia y una crisis de conciencia en los ciudadanos.

Palabras clave: Debilitamiento de la democracia / Democracia representativa / Representación política / Apatía política / Descontento político /Corrupción política / Crisis política / Francia / Europa.

Abstract: The article analyzes the current situation of representative democracy, which seems to be in crisis. It points out that, in spite of the lack of credibility or reproaches made to the political institutions, due to corruption, economic crisis, globalization, religious discourse and identity, and the incapacity of politicians to satisfy the demands of the population, the crisis escalates in two axes: lack of growth of democracy and an awareness crisis among citizens.

Key Words: Weakening of democracy / Representative democracy / Political representation / Political apathy / Political discontent / Political corruption / Political crisis / France / Europe.

\footnotetext{
${ }^{1}$ Traducción libre de Sergio Trejos Robert del artículo titulado "Une crise de la représentation politique" publicado en la revista Cités, 2004/2 (No 18), p. 41-61, editada por PUF, DOI 10.3917/cite.018.0041. Agradecemos a esta revista y a la editorial por permitirnos publicar la traducción al español en la Revista de Derecho Electoral del Tribunal Supremo de Elecciones.

"Profesora de Derecho Constitucional de la Universidad de París 1 "Pantheón-Sorbonne".
} 
Asco de la política, rechazo a los políticos, miedo a Europa, corrupción, abstencionismo, extremismo... la democracia representativa parece estar en crisis. En Francia, como en la mayoría de los países, a pesar de que ciertos mecanismos de democracia directa como el referéndum permiten clasificar nuestro régimen dentro de las democracias semidirectas, la democracia es esencialmente representativa. Por medio de la representación política, los actos llevados a cabo por los representantes políticos le son atribuidos al pueblo como si este los hubiera adoptado. Al obedecer las reglas adoptadas por nuestros representantes, se supone que nos obedecemos a nosotros mismos. Pero el problema es justamente que los franceses ya no parecen sentirse verdaderamente representados por los políticos. Su desdén parece tan profundo que a menudo ya ni siquiera se esfuerzan por ir a votar, incluso si el abanico político dentro del cual pueden elegir ha sido considerablemente extendido ${ }^{2}$. Lógicamente, el rechazo a la política y el abstencionismo favorecen enormemente a los partidos extremistas y en particular a los que, cobijándose con ella, vuelven a poner en tela de duda la democracia.

Estos problemas no solamente atañen a Francia. Muchos otros países son afectados por la corrupción, el abstencionismo y el auge del extremismo, sobre todo en Europa Occidental, pero también en otras regiones del mundo, cualquiera que sea su régimen político ${ }^{3}$. Tampoco es que sean del todo nuevos. Sin embargo, están ligados al desarrollo de fenómenos tales como la crisis económica, la globalización, el retorno al discurso religioso y

\footnotetext{
${ }^{2}$ Así, en las elecciones legislativas del 9 y 16 de junio de 2002, las tasas de abstencionismo llegaron al 35,59\% en la primera ronda y 39,68 \% en la segunda ronda, cuando los electores tenían opción entre 22 familias políticas (*la autora utiliza la palabra familia y no partido) en la primera ronda y 13 en la segunda. Estos números tan elevados se explican, no obstante, en parte por el contexto específico de esta elección: el rechazo de la cohabitación y la presencia de la extrema derecha en la segunda ronda de la elección presidencial del 5 de mayo del 2002.

Nota del traductor (NT): En Costa Rica, en las elecciones presidenciales y legislativas del 2018, el abstencionismo fue de $34,30 \%$ en la primera ronda y de $33,55 \%$ en la segunda. En las presidenciales y legislativas del 2014 fue de $31,8 \%$ en la primera ronda y de $43,5 \%$ en la segunda.

Es un tema que el Tribunal Supremo de Elecciones ha estudiado con profundidad. En "Participación y abstencionismo: Serie histórica elecciones presidenciales 1982-2018" (Tribunal Supremos de Elecciones, 2018) se puede apreciar que el abstencionismo se dispara entre las elecciones de 1994 a 1998 al pasar del 18,9\% al $30 \%$. Se puede igualmente consultar "Abstencionistas en Costa Rica: ¿Quiénes son y por qué no votan?" (Raventós Vorst, 2005) y "Respuestas ciudadanas ante el malestar con la política: Salida, voz y lealtad" (Raventós Vorst, 2011).

3 Desde hace mucho tiempo, el abstencionismo es importante en Estados Unidos de Norte América (régimen presidencial) y en Suiza (régimen directorial), igualmente en los regímenes parlamentarios (países de la Unión Europea). En cambio, el modo de escrutinio parece tener mayor incidencia en la presencia de partidos extremistas: en la medida que el escrutinio a una sola ronda lleva al bipartidismo, no emergen de manera significativa en los países -bastantes pocos- que tienen este tipo de escrutinio como, por ejemplo, en Gran Bretaña y en los Estados Unidos de Norteamérica.
} 


\section{DERECHO ELECTORAL}

una crisis de identidad ${ }^{4}$. Los aspectos constitucionales de esta crisis se explican parcialmente por la evolución de la organización y de la práctica de las instituciones políticas. Pero, sobre todo, lo novedoso de esta crisis parece residir en el hecho de que los ciudadanos hayan tomado conciencia, más que nunca, de la complejidad y de los límites de la democracia representativa.

¿Se está realmente en presencia de una "crisis"? Sin duda, si se entiende por ello un periodo difícil, una "situación tensa de la que depende el retorno al estado normal"5. Sin embargo, lejos de hipótesis pesimistas, puede considerarse que, si es que la hay, no es una crisis que afecte la existencia de la democracia misma, se trata más bien de una crisis de adolescencia de la democracia representativa. Con todo lo que conlleva de preocupante, por los desbordes a los que puede conducir, y de alivio, ya que es un progreso decisivo hacia la edad adulta. Más allá de estos problemas que traducen un desencanto doloroso, se percibe claramente una crisis de identidad, una toma de conciencia y una revuelta frente a la complejidad y los límites de la democracia representativa. No obstante, estos fenómenos reflejan esencialmente una mayor madurez de los ciudadanos que, mayoritariamente, no desean replantearse la democracia, sino que quieren una más real. Detrás de las dos grandes categorías de reproches generalmente formulados contra las instituciones, emergen los aspectos esenciales de esta crisis. La incapacidad de los políticos para cambiar nuestras vidas proviene sobre todo de: (I) una crisis de crecimiento de la democracia y la mejor comprensión de las debilidades de nuestra democracia representativa refleja sobre todo una crisis de conciencia de los ciudadanos (II).

\section{Crisis de Crecimiento, el leviatán Se Revienta}

Durante siglos, se ha percibido al Estado como el único marco de la vida política. Bajo el antiguo régimen, la soberanía del rey era asimilada a la del Estado. Al hacerse soberano en lugar del rey, el pueblo se asimiló al Estado

\footnotetext{
${ }^{4}$ Estos problemas, evidentemente, no son específicamente constitucionales. Pero algunos de ellos se explican, aunque sea parcialmente, por la evolución de las instituciones o de la práctica institucional, y todos tienen una incidencia en la percepción de las instituciones políticas. Hay que tener en mente las interacciones constantes entre estos elementos extrajurídicos y las reglas de derecho constitucional para estudiar los problemas constitucionales planteados por esta crisis.

5 NT: Si bien la autora ha utilizado el diccionario Larousse, nosotros hemos preferido traducir directamente del texto.
} 


\section{DERECHO ELECTORAL}

del cual toleraba el poder sólo porque encarnaba el suyo. Los ciudadanos podían entonces sentirse fácilmente representados por el Estado, único marco, sencillo de identificar, fácil de personificar, y cuyos poderes en todos los aspectos parecían ilimitados por el principio mismo de la soberanía 6 . Pero, bajo la influencia conjugada de una internacionalización de relaciones y de la voluntad de establecer una mayor democracia, la separación de los poderes se ha profundizado y extendido considerablemente. El poder del Estado entonces está $(A)$ dividido y limitado entre diversas instituciones políticas y (B) parece enfrentarse al desarrollo de los poderes privados.

\section{a) LA DILUCIÓn DE LOS PODERES DEL ESTADO EN DIVERSAS INSTITUCIONES}

La crisis de la democracia representativa se explica en parte por la evolución del marco y de las modalidades de esta representación. Los ciudadanos ya no están representados solamente por una institución en el marco del Estado, sino por numerosas instituciones en diversos escenarios. Desde luego y por supuesto, pueden encontrar dificultades para identificar a sus representantes y tener un sentimiento de dilución de los poderes y, por lo tanto de las responsabilidades. Dicho sentimiento se refuerza por el hecho de que los políticos evocan -a menudo- los límites de su poder para justificar su ineptitud para cambiar la vida de los ciudadanos. Sin embargo, esta evolución es producto de una garantía esencial de la democracia: la separación de los poderes. "Es una experiencia eterna que todo hombre investido de autoridad abusa de ella [...] Para que no se abuse del poder, es necesario que le ponga límites la naturaleza misma de las cosas" (Montesquieu, 2005, p. 144). Este principio ha sido aplicado no solamente en el plano horizontal, al interior del Estado, entre los tres poderes evocados por Montesquieu, sino también en el plano vertical, entre el Estado y los poderes políticos infra y supra estatales.

Se constata, en primer lugar, una evolución de la separación horizontal de los poderes. El principio de una separación entre los poderes legislativo, ejecutivo y jurisdiccional evidentemente no es novedoso en Francia. Sin embargo, la implementación y el funcionamiento de estos poderes han variado de manera sensible en estos últimos años y, sobre todo, estas variaciones han afectado la representación de los ciudadanos en el seno del Estado.

\footnotetext{
${ }^{6}$ Definida por Jean Bodin, en 1576, en Los seis libros de la República, como el "poder de impartir órdenes y constreñir sin recibir órdenes ni ser constreñido" (pp. 88-89).
} 


\section{DERECHO EIECTORAL}

Bajo la III y la IV República, los ciudadanos estaban representados principalmente por la Asamblea Nacional, único órgano del Estado cuyos miembros eran elegidos mediante el sufragio universal directo y que, además, disponía de un poder legislativo ilimitado y casi incontrolado7. Los representantes del pueblo tomaron el lugar del soberano y abusaron de su poder, en particular, cuando abandonaron todos los poderes en manos de Pétain 8 por medio de la ley del 10 de julio 1940. Bajo la IV República, la inestabilidad gubernamental condujo al replanteamiento de las instituciones ${ }^{9}$.

El objetivo, bajo la V República, consiste en reequilibrar los poderes en beneficio del Ejecutivo. Pero pronto el presidente de la República, también elegido mediante sufragio universal directo a partir de 1962, domina las instituciones. En la práctica $-y$ no en el derecho-, se entiende que el gobierno está bajo su bota y que la Asamblea debe apoyarlo bajo el riesgo de una disolución. Durante estos períodos de práctica presidencialista de la Constitución, los franceses pueden identificar con claridad a sus representantes, el más importante -sin lugar a dudas- es el presidente. Para su elección la tasa de abstencionismo es tradicionalmente la más baja ${ }^{10}$. La alternatividad es entonces muy clara entre la izquierda y la derecha que dirigen sucesivamente la mayor parte de los poderes. La contra-partida de esta simplicidad es una amplitud de los poderes presidenciales que son poco limitados por los otros poderes, y que no parecen terminar más que al finalizar el mandato presidencial (Cohendet, 2002a). Por ello, las elecciones legislativas se vuelven menos importantes de lo que eran antes a los ojos de los franceses, lo que contribuye a explicar el incremento de las tasas de abstencionismo para estas elecciones ${ }^{11}$. Así, en la primera ronda de las

\footnotetext{
${ }^{7}$ Un presidente elegido por los parlamentarios y un jefe de gobierno desprovisto, en los hechos, del arma esencial que es el derecho de disolución y consecuentemente inestable, poco podían limitar los poderes de esa Asamblea. 8 NT: Para que el lector costarricense entienda el contexto de este párrafo, es bueno recordar que Pétain fue quien negoció la rendición del Estado francés al nazismo durante la Segunda Guerra Mundial. Las inclinaciones antisemitas y fascistas afines al nazismo del político francés posiblemente incidieron en su decisión.

${ }^{9}$ La estructuración de una mayoría al rededor del gobierno no fue posible, esencialmente por que, por una parte, el presidente evitaba elegir como primer ministro a una personalidad fuerte que hubiera podido ser el líder de la mayoría y, por otra parte, si bien el primer ministro finalmente había sido dotado del derecho de disolución, sus limitantes, tanto en derecho, pero sobre todo en los hechos por el descrédito de este poder, no le permitieron utilizarlo eficazmente.

${ }^{10}$ Es habitualmente del $20 \%$ en la segunda ronda; sin embargo, puede conocer fluctuaciones importantes: cerca del $85 \%$ de los votantes en la primera ronda de las presidenciales de 1965 y solamente $64,5 \%$ en la segunda ronda de las presidenciales de 1969. En el 2002, siempre para las presidenciales, el porcentaje de votantes fue del 71,6 en la primera ronda y 79,41 en la segunda.

11 NT: El porcentaje de abstencionismo, en Costa Rica, tradicionalmente ha sido más alto en las elecciones municipales. En el 2002 fue de 77,2\%, en el 2006 de 76,2\%, en el 2010 de 72,1\% y en 2016 de 64,6\%. Vid.: Cascante Matamoros, 2019; Cascante Matamoros, 2016 y Zamora Chavarría, 2016.
} 
legislativas del 2002, cerca de $60 \%$ de los abstencionistas estiman que estas elecciones tendrán consecuencias poco o nada importantes para sus vidas $^{12}$.

En caso de cohabitación ${ }^{13}$, la percepción de la representación política se modifica profundamente. Existe una impresión de división de la representación entre, por una parte, la mayoría parlamentaria y el gobierno que determina y conduce la política de la Nación y, por otra parte, el presidente, reducido esencialmente a un rol de árbitro y de garante. La repartición de los poderes es mucho más equilibrada, y prácticamente todos los franceses se sienten representados por alguno de estos órganos (Cohendet, 1993). Pero unas interpretaciones discutibles de la Constitución y una imagen deformada de la cohabitación conducen a una impresión de cogestión, de confusión de poderes y de dilución de las responsabilidades.

Durante este medio siglo, se asiste paralelamente al surgimiento del poder jurisdiccional. Los jueces judiciales y administrativos ${ }^{14}$ han afirmado su poder $y$, en cierta medida, su independencia. El juicio de ciertos casos ha demostrado que la corrupción y los abusos del poder de los representantes pueden a veces ser limitados por el poder jurisdiccional. Pero, bajo la $\mathrm{V}$ República, principalmente el juez constitucional se convierte en una institución importante. Concebido, en un inicio, para ser el "guardián del Ejecutivo" contra el Legislativo, se vuelve un defensor del parlamento, pero sólo en cierta medida, ya que no controla la constitucionalidad de los actos del Ejecutivo, particularmente los del presidente ${ }^{15}$. Consigue legitimidad -más que nada- de su posición de garante de los derechos humanos. Hace prevalecer la voluntad del pueblo, expresada en la Constitución, a la de sus representantes,

\footnotetext{
12 Este fenómeno es particularmente claro entre los obreros y los electores de Arlette Laguiller y de Jean Marie le Pen. Sondeo Sofres realizado para Le Monde, publicado el 15 de junio 2002. NT: Laguiller fue candidata en varias ocasiones para el partido "Lucha Obrera" (como su nombre lo indica de extrema izquierda) mientras le Pen para el partido "Frente Nacional" (como su nombre también lo indica de extrema derecha) iCuriosamente pareciera ser un punto donde la extrema derecha e izquierda convergen!

${ }^{13}$ NT: "Se entiende por cohabitación la situación de un jefe de Estado y una mayoría parlamentaria políticamente antagónicos" (Cohendet, 2013, p. 325).

${ }^{14}$ NT: En Francia el juez administrativo es competencia del Consejo de Estado que se encuentra dentro del poder ejecutivo y no del judicial como sucede con la Jurisdicción Contenciosa Administrativa y Civil de Hacienda. El separar la jurisdicción administrativa del poder judicial es consecuencia en parte de la desconfianza que se arrastra hacia los jueces desde la Revolución Francesa. Se debe indicar; sin embargo, que existen algunos tribunales a lo interno del Poder Ejecutivo como por ejemplo el Tribunal Administrativo Ambiental adscrito al MINAE.

${ }^{15}$ La mayoría de los actos del presidente son actos administrativos cuyo control es ejercido por el Consejo de Estado. Sin embargo, este último rechaza controlar los actos dichos "de gobierno", referentes a las relaciones entre los poderes públicos constitucionales y los actos diplomáticos, bajo el argumento de que son demasiado políticos. Algunos de estos actos podrían, sin embargo, ser el objeto de un control de constitucionalidad.
} 


\section{DERECHO ELECTORAL}

expresada en la ley; interviene activamente en la interpretación de la Constitución y cabe preguntarse si se ha convertido -él mismo- en un representante del pueblo (Troper, 1990). Es un hecho, por lo menos, que es un límite al poder de ciertos representantes de los ciudadanos.

Ergo, la representación del pueblo ya no está siempre concentrada en un órgano con poderes muy extendidos, parlamento o presidente; se divide, de manera más o menos clara según el contexto político, y en todo caso, es más limitada de lo que era antes por el poder jurisdiccional. Las garantías democráticas son relativamente mayores que antes, pero la representación política se ha vuelto -entonces- más compleja y difícil de comprender para los ciudadanos.

Se constata, en segundo lugar, una mayor evolución de la separación vertical de los poderes.

Como el poder es casi siempre el rival del poder, el gobierno general estará siempre alerta para contener las usurpaciones de los gobiernos estatales, y éstos obrarán de igual modo respecto al gobierno general. El pueblo podrá arrojar su peso en cualquiera de los dos platillos de la balanza y hacerlo preponderar en todos los casos. Si cualquiera de los dos invadiese sus derechos, podrá utilizar al otro como medio para enderezar la situación. (Hamilton, s.f., p. 112$)^{16}$.

El principio de la separación vertical de los poderes no sólo concierne al régimen federal evocado por Hamilton, sino que también la descentralización, de la cual Tocqueville mostró su importancia para iniciar a los ciudadanos a la vida política y evitar el despotismo del Estado (1981, p. 133 $)^{17}$. Aquí también, el progreso de la democracia genera que la representación política se vuelva más compleja. El incremento de la descentralización y la politización de las elecciones locales acentúan la división de la representación y de los poderes entre el Estado y los entes descentralizados territorialmente ${ }^{18}$.

\footnotetext{
16 NT: Se ha consignado el extracto de una traducción al español de la obra. Recuperado de: http://libertad.org/media/El-Federalista.pdf

17 Ver: Tocqueville, 1981 a, p. 133.

${ }^{18}$ Esta tendencia ha sido confirmada por la revisión constitucional del 28 de marzo 2003 relativa a la organización descentralizada de la República.
} 
La construcción de la Unión Europea acentúa este fenómeno. Ahora, los gobernantes invocan con frecuencia la UE para justificar su impotencia. Por otro lado, desde la Segunda Guerra Mundial, el desarrollo considerable del derecho internacional conduce a una autolimitación de los Estados, en particular, en materia de derechos humanos. A este nivel, se asiste igualmente a un crecimiento del poder jurisdiccional, particularmente en el marco del Consejo Europeo, en beneficio de la Corte Europea de los Derechos Humanos.

Por eso, la identidad política -el sentimiento de pertenencia a una colectividad política- ya no se concentra en el Estado, sino que se multiplica en diferentes niveles. Se es ciudadano francés y europeo, y también se dispone de un poder de acción política a nivel de la municipalidad, del departamento y de la región ${ }^{19}$. Si se concibe la soberanía del pueblo como la autonomía de los ciudadanos, entonces se puede considerar que -ahorase ejerce esta autonomía en diferentes marcos geográficos. Así, nosotros los ciudadanos no somos menos soberanos de lo que éramos antes, pero podemos ejercer nuestra soberanía en diferentes escenarios. Asimismo, para defender nuestros derechos fundamentales, que son la base de la democracia, podemos actuar no solo a través de las instituciones del Estado, sino también contra el propio Estado en una jurisdicción supranacional ${ }^{20}$. Sin embargo, estos adelantos son percibidos por algunos como un resquebrajamiento inquietante de nuestra ciudadanía ${ }^{21}$.

\footnotetext{
${ }^{19}$ Las municipalidades y los departamentos existen desde hace mucho tiempo, pero estas colectividades tenían un carácter mucho menos político. Las regiones y la Unión Europea son marcos mucho más recientes.

${ }^{20}$ La historia ha mostrado, particularmente después de la Segunda Guerra Mundial, que los Estados pueden violar gravemente los derechos humanos, lo que genera un peligro mayor para la paz, por ello, se reconoció el derecho de los ciudadanos a recurrir a la Corte Europea de los Derechos Humanos contra el Estado. NT: En Latinoamérica, los funcionarios del Estado durante las dictaduras militares fueron -sin lugar a dudas- la principal amenaza a los derechos humanos. Bajo el argumento de la "seguridad nacional" se cometió todo tipo de atropellos a la dignidad humana: desde ejecuciones extrajudiciales hasta desapariciones forzadas. La criminología contemporánea estudia estas sombrías páginas de la historia. Solamente por citar Zaffaroni: (Zaffaroni, 2005, pp. 42-48); (Zaffaroni, 2013, pp. 183-196); y (Zaffaroni, 2017, pp. 445-474).

Cabe destacar el papel protagónico que ha tenido la Corte Interamericana de Derechos Humanos.

${ }^{21}$ Para esclarecer el problema de las relaciones entre la soberanía del pueblo y la división vertical de los poderes, la Corte Suprema de los Estados Unidos de Norte América ha desarrollado la teoría de la doble soberanía de los ciudadanos, que se ejerce en el marco de los Estados miembros y el del Estado federal. Pero si se concibe la soberanía del pueblo como siendo esencialmente la autonomía de los ciudadanos, es preferible referirse a los diferentes marcos de ejercicio de la soberanía.
} 


\section{DERECHO EIECTORAL}

\section{b) ¿LA RENUNCIA DEL ESTADO FRENTE A LOS PODERES PRIVADOS?}

Para evitar el nuevo despotismo, Tocqueville subrayaba también la importancia de otros contra-poderes frente al Estado, en particular el poder asociativo (Tocqueville, 1981a). De hecho, la experiencia de los regímenes totalitarios confirmó que un Estado que controla todos los poderes, particularmente el económico, religioso y mediático, es necesariamente antidemocrático y que deben existir contra-poderes exteriores al Estado capaces de limitar su poder. Sin embargo, desde hace algunos años, es válido preguntarse si se asiste a un nuevo desequilibrio de los poderes, esta vez, en beneficio de poderes privados. Mientras que Tocqueville pensaba en el rol benéfico de múltiples asociaciones con un peso similar entre ellas, se observa la influencia de grupos de presión que frecuentemente dependen -esencialmente- de su peso financiero y de su orientación política. En diversos ámbitos, se puede cuestionar la representatividad de los grupos vinculados a las decisiones políticas como las asociaciones familiares en la discusión acerca de los PACS ${ }^{22}$ o los representantes de comunidades religiosas en varios debates. Igualmente, las aseguradoras han jugado un rol central en la adopción de la ley que ha revertido la jurisprudencia Perruche (Cayla y Thomas, 2002) ${ }^{23}$. La idea de que participen asociaciones en el proceso de decisiones políticas es interesante, pero a condición de que sean realmente representativas, que no sustituyan la voluntad de la mayoría y que no se trate de una renuncia del poder político frente a los intereses económicos.

La decepción de la política se justifica a menudo por el sentimiento de que los políticos no pueden, o no quieren, actuar en ciertos ámbitos. Esto se atribuye, entre otras razones, a una globalización caracterizada por el poder de ciertos grupos y a la invocación de imperativos económicos inherentes

\footnotetext{
22 NT: Este instituto jurídico se encuentra en el artículo 515-1 del Código Civil francés: "Un pacto civil de solidaridad es un contrato celebrado por dos personas físicas mayores de edad de sexo diferente o del mismo sexo, para organizar su vida en común" (traducción de Legifrance).

Es pertinente mencionar un párrafo de François Terré y de Dominique Fenouillet:

La admisión del pacto civil de solidaridad constituye la respuesta del legislador a la demanda de acceso al matrimonio formulada por parejas homosexuales. Con el fin de suavizar la crítica que hubiera consistido en reprochar al legislador acordar el reconocimiento social a una pareja que ciertas personas consideran como "fuera de las normas", el legislador pretendió que solamente tuviera efectos patrimoniales y abarcara aspectos materiales. (Terré y Fenouillet, 2011, p. 293).

El matrimonio entre personas del mismo sexo es posible en ese país a partir de la Ley n. ${ }^{\circ} 2013-404$ del 17 de mayo 2013.

23 NT: El caso "Perruche" del 19 de diciembre de 1993 es acerca de la responsabilidad civil de un laboratorio médico por las lesiones que sufrió un no nacido. La madre decidió continuar con el embarazo creyendo erróneamente que los medicamentos que tomaba habían inmunizado al feto contra la rubéola. Este niño nació discapacitado de por vida, por lo que sus padres demandaron al laboratorio médico.
} 


\section{DERECHO ELECTORAL}

al liberalismo económico. Tiene como resultado una falta de compromiso del Estado en ciertos ámbitos, incluso una sumisión del poder político hacia imperativos económicos. Los ciudadanos se dan cuenta de la impotencia de la política para actuar sobre los problemas que más los afectan, como los despidos, el desempleo o las condiciones de trabajo. Mientras el poder de los patronos es cada vez más difícil de soportar para muchos asalariados ${ }^{24}$ y que es aún más poderoso debido al desempleo, los franceses pueden constatar que las cámaras patronales desempeñan un papel público y notorio en la elaboración de las leyes, las cuales, muy a menudo, tienden justamente a incrementar su poder ${ }^{25}$. Asimismo, si la protección del medio ambiente se ha vuelto un problema esencial para muchos franceses, al punto de que el presidente de la República se ha comprometido en inscribir el derecho humano al ambiente en la Constitución; ciertos grupos como las aseguradoras, han ejercido presiones sobre la comisión encargada de elaborar una carta del medio ambiente, y se puede temer que, cuando se examine este proyecto en el 2004, las presiones provenientes en particular del mundo empresarial logren archivar esta revisión de la Constitución o la vacíen de su contenido esencial ${ }^{26}$.

De esta manera, parece cada vez más sensible el peso que tienen ciertos grupos privados asociados al poder normativo o que -eventualmente- ejercen una presión más discreta o implícita sobre el poder político. De esta forma se determina la orientación de diferentes legislaciones lo que puede representar una amenaza para la eficacia de los derechos fundamentales. Por ejemplo, excesivas concentraciones en los medios de comunicación, la prensa y el sector de la edición pueden ser muy peligrosos para la libertad de expresión en cuanto a que existe el riesgo de que amenacen el pluralismo indispensable para la democracia y que el poder financiero controle la expresión de las ideas ${ }^{27}$. La limitación referente a estos poderes ha provenido a veces del legislador, en función de la orientación política de la mayoría, particularmente en la década de 1980, por las leyes relativas a los consorcios en la prensa y al financiamiento de los partidos políticos (para prohibir su

\footnotetext{
24 Se sabe, por ejemplo, que el número de suicidios ligados a la situación profesional ha aumentado considerablemente.

${ }^{25}$ Por ejemplo, en materia de legislación sobre la jornada laboral o sobre la flexibilidad laboral. Sobre la extensión del poder de los patronos (Dockés, 2004).

${ }^{26}$ Sobre la Carta del ambiente, se puede ver el número especial de la revista jurídica del ambiente de septiembre 2003. NT: La Carta del ambiente fue adoptada en el 2004. Al no ser un experto en materia de derecho ambiental no me aventuraría en afirmar que no haya sido vaciada de contenido. Se puede ver en el siguiente link : http://www.legifrance.gouv.fr/Droit-francais/Constitution/Charte-de-I-environnement-de-2004 consultado el 26 de diciembre de 2012.

27 NT: Ver a Shina, 2009.
} 
financiamiento por las empresas y así limitar el riesgo de plutocracia). Pero los límites a la concentración de los medios de comunicación han provenido -principalmente- de los órganos de control de estos representantes como el Consejo Constitucional ${ }^{28}$ y -más recientemente, aunque en pocas ocasionesde la Unión Europea ${ }^{29}$. El problema de las relaciones entre el poder político y los otros poderes -económico, religioso y mediático- no es nada nuevo, sin embargo, estos últimos años reviste un carácter particularmente visible, hasta chocante, lo que genera necesariamente el despecho de una parte de los ciudadanos ${ }^{30}$, a pesar de que la situación francesa es mucho menos inquietante que la de otros países ${ }^{31}$.

La crisis de la democracia representativa se debe, en parte, a que los ciudadanos observan una cierta impotencia de los políticos, que se explica a la vez por la división de los poderes y por cierta renuncia del Estado frente a los poderes privados. Pero también, se debe, sobre todo, a una mejor comprensión de los límites de la democracia representativa.

\section{Crisis de conciencia, el leviatán se desvela}

"El incremento del nivel educativo de la población refuerza [...] la posibilidad de criticar la acción de los representantes. Muchos de los fenómenos interpretados como síntomas de una «crisis de la representación» son consecuencias de esta evolución" (Gaxie, 1996, p. 152) ${ }^{32}$. Esta crisis se explica, en gran parte, por una toma de conciencia de los ciudadanos que, a la luz de ciertos asuntos, perciben mejor que nunca el carácter ficticio de

\footnotetext{
${ }^{28}$ La decisión 84-181 del 11 de octubre de 1984 del Consejo Constitucional acerca de una ley referente a limitar la concentración y asegurar la transparencia financiera y el pluralismo de las empresas de prensa.

${ }^{29}$ Así en el caso "Lagardère" de finales del 2003. NT: La Comisión Europea manifestó su oposición a que el grupo financiero "Lagardère" adquiriera "Vivendi Universal Publishing" y de esta forma estableciera -en los hechos- un monopolio en el ámbito de la edición. (Comunicado de prensa n. ${ }^{\circ} 137 / 12$ de la Corte de Justicia Europea. Recuperado de https://europa.eu/rapid/press-release_CJE-12-137_fr.htm?locale=FR el 13 de setiembre de 2019).

${ }^{30} \mathrm{El}$ poder religioso, que tanto ha pesado en nuestra historia, parecía haber desaparecido del escenario político de la década de los 1970 ha vuelto a ser importante, el poder mediático había sido liberado progresivamente de la tutela del poder político, sobre todo con el desarrollo del pluralismo de las radioemisora y de las televisoras en los años 1970 y 1980, hoy parece amenazado por el poder financiero, y el poder económico parecía igualmente tener menos influencia sobre el poder político en los años 1980. Sobre el poder industrial de las tabacaleras, Vid. Envoyé Spécial du $1^{\text {er }}$ abril 2004.

${ }^{31}$ Así, los lazos entre el poder financiero y el mediático son particularmente problemáticos en Italia, y, de manera general, los lazos entre el poder financiero y el político son claramente problemáticos en Japón y en los Estados Unidos de Norte América. En Suiza la victoria del líder populista Cristophe Blocher en las elecciones del 10 de diciembre 2003 ha sido saludada con entusiasmo por el medio empresarial, que se dicen "encantados", particularmente los banqueros que aprecian que defienda el secreto bancario.

32 NT: Este libro ha sido traducido al español (Gaxie, 2004).
} 


\section{DERECHO ELECTORAL}

la democracia representativa y la necesidad de controlar a los gobernantes. Consecuentemente, la comprensión de estos problemas (a) como la búsqueda de soluciones (b) refleja una mayor madurez de los ciudadanos.

\section{a) Se denuncia La ficción de La Representación}

Síntesis de la libertad y de la igualdad, la democracia descansa sobre el principio de autonomía de los individuos. Ser libre es acatar solo a las reglas que uno mismo se ha fijado. La ficción de la representación es una gran excepción a este principio. La doctrina, desde hace mucho tiempo, ha subrayado los inconvenientes de esta ficción ${ }^{33}$. Para Emmanuel Dockès, la propia palabra 'representación' "es la fuente de uno de los principales mitos del Derecho y una de sus falsificaciones más groseras" (Dockès y Lhuillier, 2001, p. 164). "El parlamento representa al pueblo. Acatar las leyes, desde luego, es obedecer a nuestros representantes, lo que sigue siendo obedecernos un poco a nosotros mismos. El concepto de la representación guarda [...] las apariencias. No obstante, el engaño sigue estando allí" (Dockès y Lhuillier, 2001, p. 185). El concepto de la representación sirve, principalmente, para legitimar y disimular el poder. El mecanismo jurídico de la representación, por el cual una persona, el representante, puede comprometer al representado y así crear obligaciones a su cargo sin que su consentimiento sea requerido, es utilizado en otras ramas del derecho, principalmente, para los menores y las personas discapacitadas ${ }^{34}$. Pero, en democracia, la teoría de la representación poco puede justificarse por la incapacidad jurídica del pueblo. Su única justificación reside -ahora- en la división del trabajo (Kelsen, 1988). Sin embargo, siempre ha implicado el riesgo de una confiscación del poder de los gobernados y, entonces, es necesario que los representantes sean realmente controlados.

\footnotetext{
33 Para Rousseau (2201), la ley debe ser la expresión de la voluntad general, la cual no puede representarse. Para Tocqueville, esta ficción y la ausencia de control de los electos puede legitimar un nuevo despotismo, el de la mayoría:

[...] hemos hecho en Europa extraños descubrimientos. La república, según algunos, no es el reino de la mayoría, como lo habíamos creído hasta aquí, es el reino de los que influyen fuertemente sobre la mayoría. No es el pueblo que dirige en este tipo de gobiernos, sino que son los que saben cómo influir en el pueblo -feliz distinciónque permite actuar en nombre de naciones sin consultarlos, y reclamar su reconocimiento pisoteándolos [...] hemos descubierto en nuestros días que hay en el mundo tiranos legítimos y santas injusticias, basta que las ejerzan en nombre del pueblo (1981b, p. 518).

34 NT: El procedimiento mediante el cual se limita la capacidad de actuar de una persona se conoce como "salvaguarda" y está regulado mediante la Ley para la promoción de la autonomía personal de las personas con discapacidad (n. $\left.{ }^{\circ} 9379\right)$.
} 
¿Cómo son las cosas bajo la $V$ República? "La soberanía nacional reside en el pueblo, que la ejerce a través de sus representantes y por medio del referéndum"35. La formulación del artículo 3 de la Constitución es ambigua en cuanto a que se refiere a dos concepciones radicalmente opuestas de la soberanía. Por un lado, la teoría de la soberanía nacional desarrollada por Siéyès, según la cual los electos representan a toda la nación y no al pueblo y que, por lo tanto, pueden no ser elegidos por medio del sufragio universal directo, ejercer un largo mandato el cual no es imperativo y ser poco controlados por los electores. Del otro lado, la teoría de la soberanía popular predicada por Rousseau, según la cual la democracia debería ser directa ${ }^{36}$, pero en vista de que todas las decisiones no pueden ser tomadas directamente por el pueblo, la elección de representantes del pueblo es un remedio -a más no haber- aceptable solamente si los electos son considerados como mandatarios del pueblo: son elegidos necesariamente por medio del sufragio universal directo, su mandato debe ser corto, puede ser imperativo y deben ser controlados estrechamente por los electores.

En la práctica, con la excepción del referéndum, es sobre todo la tesis de la soberanía nacional que se impone hoy en Francia. Esto se traduce por una falta de representatividad de los electos y por un control insuficiente de su actividad.

Para empezar, existe una zanja entre los representantes y los representados. Según Daniel Gaxie, se observa una clara división del trabajo político entre "especialistas" y "profanos":

\footnotetext{
${ }^{35} \mathrm{NT}$ : Traducción del Consejo Constitucional. Tomado de http://www.conseil-constitutionnel.fr/conseilconstitutionnel/root/bank_mm/espagnol/constitution_espagnol.pdf el 02 de enero del 2013.

En Costa Rica sucede algo similar. Si bien es cierto: "La soberanía reside exclusivamente en la Nación" (artículo 2 de la Constitución Política) y "Los Diputados tienen ese carácter por la Nación" (artículo 106), la potestad de legislar también la tiene el pueblo por la vía del referéndum según lo estipulado en los numerales 123, 124, y 129 de la Carta Magna después de la reforma operada por la Ley n. ${ }^{\circ} 8281$ del 2002.

Duverger et al, 2007; Robles Leal, 2016; Sobrado González, 2014, pp.165-184;(Hernández Valle, 2004a, pp.379400); Hernández Valle, 2004b, pp. 51-100); Trejos Robert, 2014; González Mora, 2017; Zovatto Garetto, 2015; Alfaro Calderón y Madriz Pérez, 2008; Sobrado González, 2007; Esquivel Faerron, 2008; Gómez Campos, 2010; y García Pandolfi y González Montero, 2008.

36"La soberanía no puede estar representada por la misma razón de no poder ser enajenada; consiste esencialmente en la voluntad general, y la voluntad no se representa; es la misma o es otra: no hay término medio. Los diputados no son, ni pueden ser representantes del pueblo, sino sus comisionados, y no pueden resolver nada, en definitiva. Toda ley que no haya sido ratificada por el pueblo en persona es nula, y no es ley" (Rousseau, 2001, p. 125). Es en sus Consideraciones sobre el gobierno de Polonia donde admitirá la necesidad de electos, pero estrechamente controlados por el pueblo. Duguit subraya que "a pesar de la argumentación lógica de J.J Rousseau, el gobierno representativo se ha (...) instituido en todos los países civilizados y se admite la existencia de la soberanía y la posibilidad de su representación" (2000, p. 218).
} 


\section{DERECHO ELECTORAL}

Todas las encuestas de opinión confirman esta situación de exterioridad de los que son -a pesar de todo y oficialmenteciudadanos dotados de una parcela de soberanía. Sólo una minoría de hombres y de mujeres -alrededor del $15 \%$ de las personas mayores de 15 años- se declara "muy" interesada por la política [...] y la probabilidad de prestar interés en los asuntos políticos se incrementa regularmente con el nivel de escolaridad y la posición social. Sin embargo, cerca de la mitad de la población es casi que indiferente a los asuntos sociales definidos como "políticos" y el resto, aproximadamente el $35 \%$ se sitúa en niveles intermediarios de interés" (Gaxie, 1996, p. 20) ${ }^{37}$.

El campo político se constituye en una "esfera cerrada" que tiende a replegarse sobre sí misma. Es sobre la base de la "«aptitud propiamente política» que se fundamenta la «superioridad» de los representantes con respecto a sus «mandatarios» [...] la división del trabajo crea la especificidad sobre la que descansa su autoridad" (Gaxie, 1996, p. 149).

Ello conduce a situaciones bastantes paradójicas. Los ciudadanos votan por políticos muy diferentes a ellos, en razón de sus competencias específicas, pero al mismo tiempo se sienten alejados de esta clase política que no es a su imagen. La profesionalización de la política acrecienta la distancia entre representantes y representados, sobre todo para los más desamparados, que se identifican difícilmente con la élite política y que se someten tanto más a los electos en la medida que no se sienten capaces de controlarlos (Gaxie, 1996). Esto se traduce además por una visión a veces muy diferente de las cosas entre representantes y representados. Por ejemplo, los diputados están mucho menos interesados que los ciudadanos en la protección del medio ambiente y conscientes de la gravedad de esta situación.

Durante estos últimos años, el desprecio por la política ha sido determinado, en gran parte, por la decepción provocada por la ausencia de grandes cambios a raíz de la alternancia de partidos y por los "juicios". De hecho, especialmente desde la caída del muro de Berlín, la divergencia entre izquierda y derecha parece haberse esfumado por lo menos hasta un

\footnotetext{
${ }^{37}$ En la 1. a vuelta de las elecciones del 2002, cerca de los tres cuartos de los abstencionistas (71\%) dicen que este escrutinio les interesa poco ( $41 \%$ ) o nada (30\%), y de los que han votado, $69 \%$ se declaran interesados por estas elecciones (27\%) están poco interesados y 4\% no lo están del todo. Ver: Le Monde, 15 de junio 2002.
} 


\section{DERECHO ELECTORAL}

periodo reciente ${ }^{38}$. Desde la mitad de 1980 , en Francia, los partidos ya no presentan programas muy precisos y claramente marcados entre la izquierda o la derecha, sino más bien grandes orientaciones destinadas a recoger los votos del centro, lo que acentúa este sentimiento. La primera causa del abstencionismo, principalmente, reside en el hecho de que los electores "no confían en los políticos en general". Es en efecto la primera causa invocada por los abstencionistas ( $42 \%$ en promedio, $50 \%$ entre los obreros y asalariados y $69 \%$ entre los electores de J.M. Le Pen en 2002) (Le Monde, 15 junio de 2002). Sin embargo, esta opinión es diferente para el conjunto de la población, ya que $68 \%$ de los franceses desaprueban las críticas del FN (Frente Nacional ${ }^{39}$ ) contra la clase política. Las relaciones de los franceses con sus representados son ricas en paradojas, particularmente en este punto. Critican la corrupción de los políticos, y sin embargo, suelen reelegir candidatos cuya corrupción ha sido demostrada. Y, sobre todo, manifiestan la mayor desconfianza con los electos precisamente cuando la corrupción es por fin sancionada por la justicia -por lo menos en cierto número de casos-. De hecho, la corrupción de los políticos no es un fenómeno nuevo ${ }^{40}$, tampoco su denuncia, es más bien la sanción de una parte de estos casos la que ha mostrado la amplitud del problema y suscitado reacciones de rechazo. Si bien es cierto que es difícil medir la evolución de la corrupción bajo la $\mathrm{V}$ República con precisión, ya que hasta hace poco muchos de los casos eran enterrados, al menos parece evidente que el general de Gaulle no hubiera permanecido inactivo si quienes lo rodeaban habrían sido implicados en asuntos de este tipo y difícilmente lo hubiéramos visto evadiendo la justicia. Resulta bastante lógico que los franceses estén decepcionados cuando el jefe de Estado puede erigir "la cero tolerancia" como el credo de su política y, al mismo tiempo, ser prácticamente intocable el tiempo que presida los Elíseos. Ni la decisión de un Consejo Constitucional compuesto entonces de cinco exministros de nueve miembros ni la corte de casación ni tampoco la posición de la comisión presidida por Pierre Avril, cuyos miembros han sido todos elegidos por el propio presidente, han podido borrar la imagen de irresponsabilidad

\footnotetext{
${ }^{38}$ Cabe destacar el discurso de la extrema derecha que busca presentarse de esta forma como la única alternativa existente.

39 NT: Ver nota 13.

${ }^{40}$ Este problema se ha presentado durante toda nuestra historia; ya existía en la Grecia Antigua y en la época de la Revolución: por ejemplo, en 1795 Lacharrière notaba que "dentro de los directores, hubo inteligentes y honrados, pero no eran los mismos", y designa un "Barras" "traficando de todo, todo el tiempo y con todo el mundo".
} 
que afecta gravemente la función presidencial ${ }^{41}$. Estas decisiones han reforzardo un sentimiento de aislamiento de una clase de intocables. Están marcadas por una interpretación curiosa y difícilmente aceptable del principio de igualdad de los ciudadanos frente a la ley y de la separación de los poderes ${ }^{42}$. Por añadidura, cuando la responsabilidad penal de la mayoría de los miembros del ejecutivo ha sido aumentada en estos últimos años, el presidente de la República constituye una excepción (L'Hôte, 2001).

\section{b) LA BÚSQUEDA DE UNA DEMOCRACIA RENOVADA}

El mito de la unidad del pueblo y los fenómenos más chocantes de esta crisis no deben deformar nuestra visión de la realidad. No solo es uno, sino que son varios los cuestionamientos a las instituciones. Así, las causas y las manifestaciones de esta crisis son muy diversas dependiendo de las ideas, a menudo ligadas al origen socioprofesional, al nivel cultural o a la edad. El abstencionismo es particularmente fuerte entre las personas desfavorecidas. En la primera vuelta de las elecciones legislativas del 2002, la tasa de abstencionismo fue del $35,5 \%$, pero asciende al $44 \%$ entre los obreros y llega al $59 \%$ entre los desempleados. Por otro lado, esta tasa es dos veces más elevada entre los jóvenes que dentro de los mayores de 50 años ${ }^{43}$.

Los cuestionamientos a la democracia representativa y la búsqueda de nuevas vías para la expresión política hoy se realizan principalmente en tres direcciones: la puesta en duda de la democracia, la búsqueda de medios para mejorarla y la micro política.

\footnotetext{
${ }^{41}$ Durante años, fue evidente para la casi totalidad de la doctrina que la responsabilidad del presidente por los actos cometidos fuera del ejercicio de sus funciones podía ser emprendida frente a los tribunales de derecho común, particularmente, frente a las jurisdicciones penales. En vista de esta interpretación, es claro que el Consejo Constitucional, en su fallo del 22 de enero de 1999, la corte de casación en su sentencia del 10 de octubre 2001 y la comisión Pierre Avril en su reporte al presidente del 12 de diciembre 2002, han adoptado cada uno siguiendo, por cierto, un razonamiento diferente- una visión del problema que conduce a reforzar considerablemente el carácter "intocable" del presidente durante su mandato, y una revisión constitucional ha sido emprendida para conseguir esta ampliación en la versión propuesta por la comisión Pierre Avril.

${ }^{42}$ Se entiende que los fueros de inmunidad son un obstáculo para que el poder jurisdiccional limite los abusos de quienes detentan el poder ejecutivo (Cohendet, 2002b, p. 321).

${ }^{43}$ En la primera vuelta de las elecciones legislativas del 2002, la tasa de abstencionismo fue del $51 \%$ entre los de $25-34 \%$ (46 \% entre los de 18-24 años), cuando es siempre inferior al $25 \%$ entre los de 50 años o más ( $23 \%$ en la sección de los 50-64 y 24\% para los de 65 años y más). Ver: Le Monde, 15 de junio 2002. NT: A partir del estudio "Abstencionistas en Costa Rica: ¿Quiénes son y por qué no votan?" se puede concluir que, aquí, las personas jóvenes también se alejan de las urnas. El porcentaje de abstencionistas es mayor dentro de los sectores desfavorecidos de la sociedad y -un dato interesante que no aporta la autora- las mujeres votan más que los hombres (Raventós Vorst, 2005).
} 
La primera vía es la de la extrema derecha, cuyas ideas han convencido cerca de un francés de cada cuatro. La adhesión a estas ideas es muy fuerte entre las personas desprovistas de títulos y entre los obreros, comerciantes, artesanos y empresarios ${ }^{44}$. El discurso de estos partidos y los actos de sus simpatizantes recuerdan a veces la atmósfera de los años 3045: denuncia de los políticos "todos corruptos", aumento del antiparlamentarismo, desprecio por los derechos humanos, sexismo, racismo, antisemitismo, acciones violentas contra algunas personas en razón de su color de piel o del origen de su nombre. El cuestionamiento de la democracia representativa en nombre de una democracia supuestamente más real apunta aquí, en realidad, a negar la democracia. La ideología de la extrema derecha cuestiona la separación de los poderes y los derechos humanos para preferir el todo-poderío del Estado, y vuelve a poner en duda la visión tradicional de la representación concedida como un mandato, una relación de dos voluntades autónomas, para mejor justificar la soberanía del presidente -figura moderna del príncipe absoluto- concebida para encarnar la unidad del pueblo en el Estado (Beaud, 1987). Estas ideas siguen siendo minoritarias, ya que $70 \%$ de los franceses consideran que el FN (Frente Nacional) ${ }^{46}$ representa un peligro para la democracia ${ }^{47}$.

La segunda vía, al contrario, consiste en mejorar la democracia (Robert, 2002 y Duhamel, 2002).

Las propuestas hechas en este sentido apuntan primero a incrementar la participación del pueblo en el poder normativo. ¿Será necesario cuestionar

\footnotetext{
44 Ver: Encuesta anual del Instituto TNS-Sofres para Le Monde y RTL, publicado en Le Monde del 10 de diciembre 2003.

${ }^{45}$ NT: Muchos intelectuales costarricenses también encuentran fuertes similitudes entre la actualidad nacional y los años 30. Para profundizar en esta temática se puede consultar a (Díaz Arias, 2015).

${ }^{46}$ Ver nota 13.

47 Ver: Le Monde, 10 de diciembre 2003. NT: El apoyo a este partido de extrema derecha ha crecido considerablemente desde que se publicó este artículo en el 2004. En la primera vuelta de las elecciones presidenciales del 2007 obtuvo 10,44\% de los votos. En la primera vuelta de las presidenciales del 2012 el $17,90 \%$. En la primera vuelta de las presidenciales del 2017 el 21,30\% logrando de esta forma pasar a la segunda vuelta donde obtuvo $33,90 \%$ de los votos.

En las elecciones europeas del 2009 obtuvo 6,34\% de los votos. En las del 2014 el $24,86 \%$ y en las de 2017 el $23,34 \%$ siendo el partido con más votos.

Datos tomados de la página web del Ministerio del Interior francés en: https://www.interieur.gouv.fr/Elections/Les-resultats el 23 de setiembre de 2019.

Francia no es el único país donde este tipo de agrupaciones políticas tienen éxitos en las urnas: En el 2016 Donald Trump fue elegido presidente en los Estados Unidos de Norte América después de una campaña política donde el tema central fue la xenofobia (construir un muro fronterizo ha sido su principal promesa). Ese mismo año, Rodrigo Duterte fue elegido presidente de las Filipinas después de prometer ejecuciones extrajudiciales a los traficantes de droga. Jair Bolsonaro asumió la presidencia de Brasil el 01 de enero 2019 realizando esta misma promesa abiertamente violatoria de las más elementales garantías penales- durante las elecciones. Da la impresión de que se ha retrocedido a los años 30 del siglo XX.
} 
la democracia representativa para reemplazarla por una democracia directa? Efectivamente se podría, en un futuro relativamente cercano, implementar debates y votos por Internet. Sin embargo, la complejidad de ciertas cuestiones supone que se les debe dedicar mucho tiempo, lo que es poco posible para la mayoría de los ciudadanos. La democracia deberá, entonces, seguir siendo semidirecta. Se puede esperar que la reciente reforma sobre el referéndum local permitirá rejuvenecer este instrumento democrático. No obstante, se tendría que impedir que, por este procedimiento, se atente contra los derechos humanos ${ }^{48}$ y que se pueda recurrir a él con más frecuencia, particularmente por medio de la iniciativa popular ${ }^{49}$, sin miedo de ver resurgir el cesarismo. A menudo se evoca el problema de la tan elevada tasa de abstencionismo con ocasión de este tipo de consultas, pero debe relativizarse y la introducción de un quórum podría evitar los riesgos que ello conlleva ${ }^{50}$. Se han propuesto diferentes ideas para luchar contra el abstencionismo, importante en la mayoría de las democracias contemporáneas y que afecta tanto las elecciones como los referéndums. Las respuestas más satisfactorias consisten evidentemente en un tratamiento de las causas del abstencionismo, en particular el abismo entre los políticos y los ciudadanos. Sin embargo, hoy resurge una idea que

\footnotetext{
48 NT: Este ha sido un tema de discusión frecuente en Costa Rica. La Sala Constitucional de la Corte Suprema de Justicia, en sentencia 13313-2010 de las dieciséis horas y treinta y uno minutos del diez de agosto del dos mil diez, consideró "[...] que la potestad legislativa está sujeta a los límites dispuestos «por los tratados, conforme a los principios del Derecho Internacional» Es así como los derechos humanos establecidos en los instrumentos del Derecho Internacional Público -Declaraciones y Convenciones sobre la materia-, resultan un valladar sustancial a la libertad de configuración del legislador, tanto ordinario como, eminentemente, popular a través del referéndum".

La doctrina nacional -de forma unánime- avala esta interpretación jurisprudencial que por lo demás es de carácter vinculante.

Ver a González Mora, 2017; Carballo Madrigal, 2015; y Hernández Valle, 2004b, pp. 96-97.

${ }^{49}$ NT: Ver a Carro Zúñiga, 2017; Trejos Robert, 2017 y Hernández Valle, 2004a, pp.391-397; (Hernández Valle, 2004b, pp. 70-75.

50 En Suiza, la tasa de abstencionismo se sitúa, la mayoría del tiempo, entre $40 \%$ y $60 \%$. Sin embargo, varía considerablemente en función de la importancia de la cuestión planteada. En Francia, con ocasión del referéndum constitucional sobre el quinquenato, la tasa de abstención se elevó a $69 \%$, sin embargo, el debate era muy confuso y el resultado parecía resuelto de previo (fue adoptado con $73 \%$ de los votos). NT: En Costa Rica, el porcentaje de abstencionismo en las consultas populares es bastante alto: la consulta distrital realizada en Cóbano, Lepanto y Paquera el 7 de diciembre de 1999 arrojó un abstencionismo del 64\%; la consulta cantonal en Sarapiquí del 24 de setiembre del 2000, 87\%; la consulta cantonal en Guácimo del 28 de octubre de 2001, 73\%; la consulta distrital de Piedades Sur de San Ramón del 16 de febrero de 2003, 59\%; la consulta cantonal de Turrialba del 28 de agosto de 2005 82\%; la consulta distrital de Pejibaye del 29 de junio de 2008, 65\%; en el plebiscito de revocación de mandato celebrado en Pérez Zeledón el 18 de diciembre de 2001, 73\%; en el plebiscito de revocación de mandato celebrado en Paraíso el 20 de mayo de 2018, 80\%; y en la consulta distrital realizada en Nosara el 03 de junio de 2018, 79\%.

Excepcionalmente, la participación ha sido alta: la consulta distrital realizada en la Angostura de Santiago el 14 de abril del 2002 arrojó un abstencionismo del 16\%; el referéndum nacional del 07 de octubre 2007, 40\%; en la consulta distrital de San Isabel, San Rita y Río Cuarto del 07 de abril de 2019, 28\%.
} 
hace sonreír, la del voto obligatorio, practicada -entre otros países- en Bélgica, pero que talvez merezca una reflexión ${ }^{51}$.

Mejorar la democracia participativa implica también el desarrollo de diversos procedimientos de consulta a los electores y administrados, particularmente por medio de debates, desde asambleas vecinales hasta el nivel nacional o europeo (Dumont, 2002). Algunos avances han sido realizados: las grandes discusiones acerca de la carta del ambiente o sobre el sistema educativo -incluso si pueden ser objeto de vigorosas críticas ${ }^{52}$ al menos tienen la ventaja de recordar que la opinión de los ciudadanos es esencial sobre las cuestiones sociales y que la democracia no es la dictadura de la mayoría, sino que exige opiniones verdaderamente contradictorias.

\section{Profundizar la democracia también implica exigir una mejor} representatividad de los gobernantes. De manera general, algunos preconizan la generalización de sistemas proporcionales ${ }^{53}$ para favorecer la multiplicación de partidos políticos. Los ciudadanos podrían, entonces, elegir candidatos más cercanos a sus preocupaciones. Pero esto no se podría concebir sin modificar varios puntos de las reglas constitucionales, por una parte, para garantizar la estabilidad gubernamental y, por otra, para evitar que partidos antidemocráticos puedan encontrarse árbitros del juego político ${ }^{54}$. También es posible concebir un ajuste del modo de escrutinio que permitiría a los ciudadanos pronunciarse por un partido $y$,

\footnotetext{
51 El artículo 93 de la Constitución Política establece lo siguiente: "El sufragio es función cívica primordial y obligatoria y se ejerce ante las Juntas Electorales en votación directa y secreta". Sin embargo, el ordenamiento jurídico no establece una sanción para los abstencionistas.

52 Recientemente la multiplicación de debates -en marcos muy diversos- como lo son en las empresas, la escuela o sobre el escenario público, tal vez se trate de una simple estrategia consistente en dar la ilusión de que los participantes tienen un poder de decisión, cuando esta decisión en verdad es tomada discrecionalmente por los que han organizado estos debates. Se trata entonces de un proceso de legitimación del poder que puede, en ciertos casos, rozar con una estafa intelectual.

53 NT: Este tema actualmente se está discutiendo en Costa Rica. Ver: Hernández Valle, 2004a, pp. 361-365; Hernández Valle, 2004b, pp. 136-141; Gordienko López, 2015; Gordienko López, 2019; González Fernández, 2018; Rosales-Valladares, 2015 y Alcubilla, 2019.

${ }^{54}$ Convendría, sobre estos puntos, inspirarse del ejemplo alemán en lo que concierne el mecanismo de la censura constructiva y el control del carácter democrático de los partidos por la corte constitucional. NT: La "censura constructiva" es un mecanismo de control del canciller por parte del parlamento. Se encuentra regulada en el artículo 67 de la Ley Fundamental de la República Federal de Alemania: "El Bundestag sólo podrá plantear una moción de censura frente al Canciller Federal si elige por mayoría de sus miembros a un sucesor y solicita del Presidente Federal el relevo del Canciller Federal. El Presidente Federal deberá acceder a esta solicitud nombrando a quien resulte elegido". Traducción al español realizada por el Deutscher Bundestag tomada de https://www.btgbestellservice.de/pdf/80206000.pdf el 23 de septiembre de 2019.

Acerca de este instituto Philippe Lauvaux comenta lo siguiente: "Evidentemente que el mérito de la estabilidad política del régimen no se le puede imputar exclusivamente al artículo 67. Pero este procedimiento, del solo hecho de su existencia, también puede haber contribuido a reforzar los efectos positivos de la estructura política -sistema de partidos y régimen electoral- sobre la estabilidad gubernamental de la Alemania postguerra" (Lauvaux, 2004, p. 719).
} 
dentro de este partido por una u otra tendencia55. De manera más puntual, la falta de representatividad del Senado ha sido muchas veces subrayada. ¿Cómo los franceses podrían sentirse convenientemente representados en un país donde la segunda cámara del parlamento, que particularmente tiene el poder de bloquear las revisiones a la Constitución, ha sido constantemente dominada por una mayoría de derecha, ya que su modo de designación favorece los electores del campo por sobre los de las ciudades, despreciando el principio de igualdad del sufragio y bajo el pretexto de que representa los entes descentralizados territorialmente ${ }^{56}$ ?

Estas propuestas buscan desarrollar el control de los ciudadanos sobre sus representantes. "El pueblo inglés se figura ser libre y se engaña mucho; no lo es sino durante la elección de los miembros del parlamento; en cuanto éstos resultan elegidos, el pueblo es esclavo o no es nada" (Rousseau, 2001, p. 125). Lastimosamente, esta frase de Rousseau no ha envejecido lo suficiente. Como acertadamente lo había recomendado, el primer medio para reforzar el control de los ciudadanos sobre sus representantes consiste en mandatos cortos. En nuestra época, donde todo cambia mucho más rápido que hace dos siglos, se podría considerar reducir todos los mandatos a una duración de tres a cuatro años ${ }^{57}$. También se ha sugerido instaurar procedimientos de "Recall"58 permitiendo a los ciudadanos revocar los representantes durante el mandato ${ }^{59}$. De manera más general, algunos han deseado que se desarrollen y mejoren los mecanismos de control existentes entre los gobernantes, lo que puede lograrse por una revalorización del rol

\footnotetext{
55 Sería necesario encontrar un ajuste de este principio que permita evitar los inconvenientes que han justificado su abandono en Japón: un faccionalismo exacerbado.

56 Así, Jean Granger subraya que "inmutablemente, desde 1959, es dominado por una mayoría RPR-UDF-centrista, alcanzando 72,6 \% en 1989 y siempre superior entre 10 a 20 puntos del porcentaje que obtienen en las elecciones realizadas por medio del sufragio universal directo", demuestra el carácter desigual de esta representación, no solamente entre los ciudadanos, pero también entre los entes descentralizados territorialmente" (Duhamel y Mény, 1992, p. 968). La reforma adoptada por su ley orgánica y por la ley del 30 de julio de 2003 no modifica esta situación de manera substancial, y se puede notar que, si el Consejo Constitucional tuvo la audacia de denunciar el mantenimiento de ciertas disparidades geográficas, no tuvo el valor de modificarlas.

57 Recordemos que los mandatos duraban de uno a dos años durante la época revolucionaria, en los Estados Unidos de Norte América la cámara de representantes es elegida por dos años y en Suecia los diputados son elegidos por tres años (se trata, no obstante, de uno de los regímenes de la UE con mayor estabilidad gubernamental).

58 NT: La autora ha utilizado esta palabra en inglés. Se podría traducir por "revocación de mandato". Este instituto existe en el derecho municipal costarricense. Fue utilizado el 18 de diciembre del 2011 en el cantón de Pérez Zeledón para destituir de la función de alcalde a Luis Mendieta Escudero. Ver: Fernández Argüello y Sánchez Navarro, 1999; Fernández Argüello, 2017; Matheus Brito, 2008; Rivera Sánchez, 2006 y Chacón Murillo, 2014.

${ }^{59}$ Este tipo de procedimiento existe en ciertos Estados federados de los Estados Unidos de Norte América, en Japón y en Rumania. En Austria le permite al pueblo resolver un eventual desacuerdo entre el presidente y la mayoría parlamentaria: si el pueblo se pronuncia por el parlamento, el presidente debe renunciar $y$, en caso contrario, la asamblea es disuelta. A pesar de que nunca ha sido utilizado, es eficaz ya que se trata de un arma disuasiva.
} 


\section{DERECHO EIECTORAL}

del parlamento. Sería lógico que el primer ministro disponga del derecho de disolución para contrarrestar su responsabilidad frente a la Asamblea, en la actualidad solo el presidente de la República cuenta con este derecho60, a pesar de que -salvo caso de alta traición- el primer ministro es irrevocable. También se ha planteado la necesidad de considerar no solamente la responsabilidad política del presidente, sino también la penal, para que no sea tan limitada como lo es actualmente. Para algunos, el reequilibrio de nuestras instituciones implica la supresión de la elección del presidente por medio del sufragio universal directo ${ }^{61}$ y la elección del primer ministro directamente por los ciudadanos (Le Monde , 6 de mayo de 2002) ${ }^{62}$. Por otra parte, se ha sugerido volver a revisar el artículo 16 de la Constitución ${ }^{63}$ que puede permitirle al presidente el ejercicio de plenos poderes y extender la competencia del Consejo Constitucional para que pueda revisar algunos de sus actos. Además, la independencia de ciertos órganos encargados de controlar a los gobernantes podría garantizarse mejor, particularmente sus modos de designación, especialmente en lo que se refiere al Consejo Constitucional y el mediador ${ }^{64}$.

Estas propuestas también tienen por objeto acercar los representantes a los representados. Una evolución en este sentido sería favorecida por una prohibición de toda acumulación de mandatos, tantas veces propuesta. Tendría la ventaja de aumentar considerablemente el número de ciudadanos que participen realmente en la vida política y permitiría una diversificación sociológica de los representantes, especialmente favoreciendo el acceso de las mujeres en la vida política.

\footnotetext{
${ }^{60}$ NT: El párrafo primero del artículo 12 de la Constitución francesa contiene este instituto: "El Presidente de la República podrá, previa consulta con el Primer Ministro y con los Presidentes de las Cámaras, acordar la disolución de la Asamblea Nacional". Cabe consignar uno de los comentarios que realiza la autora en su tratado de derecho constitucional: "Existen dos grandes tipos de disolución: la victoriana, o de combate, que permite al Jefe de Estado sancionar un parlamento insumiso. Esta ha desaparecido en la mayoría de las democracias. La disolución de apoyo, o inglesa, mediante la cual el jefe del ejecutivo (de hecho, el primer ministro) procede a disolver de forma anticipada la asamblea, en un momento en que su partido todavía es popular, para favorecer la reelección de una mayoría que lo apoye" (Cohendet, 2013, pp .480-481).

${ }^{61}$ Así para los autores de la Convención para la VI Republica.

62 Ver: Le Monde, 6 de mayo 2002

${ }^{63}$ NT: El texto de la norma es el siguiente: "Cuando las instituciones de la República, la independencia de la Nación, la integridad de su territorio o el cumplimiento de sus compromisos internacionales estén amenazados de manera grave o inmediata y el funcionamiento regular de los poderes públicos constitucionales esté interrumpido, el Presidente de la República tomará las medidas exigidas por tales circunstancias, previa consulta oficial con el Primer Ministro, los Presidentes de las Cámaras y el Consejo Constitucional". Recuperado del Consejo Constitucional en: http://www.conseilconstitutionnel.fr/conseilconstitutionnel/root/bank_mm/espagnol/constitution_espagnol.pdf, consultado el 08 febrero de 2013.

64 NT: El tema de la designación de los magistrados de la Corte Suprema de Justicia es particularmente problemático en Costa Rica (Antillón, 2019).
} 
Los ciudadanos solamente pueden sentirse representados si pueden comprender el funcionamiento de las instituciones y el papel de sus representantes. Pero esto supone, por una parte, ser claros sobre la organización de las instituciones $y$, sobre este punto, el proyecto de "Constitución"65 de la Unión Europea está lejos de ser plenamente satisfactorio; por otra parte, un verdadero aprendizaje de la democracia a partir de la escuela primaria. No sólo implica un conocimiento serio de las instituciones, sino también la práctica del debate, del voto y de las responsabilidades en el seno mismo de la escuela. En fin, si los rankings de audiencia influyeran menos sobre la elección de los programas de televisión, podríamos esperar que una parte importante sea otorgada a emisiones de información política de calidad. Todas las encuestas muestran que el abstencionismo y el rechazo a lo político están a menudo ligados al nivel sociocultural.

La tercera vía es la de la micropolítica. Cada vez más, ciudadanos que se sienten completamente desamparados, indefensos en un mundo en el cual difícilmente tienen influencia, van a buscar y encontrar a través de acciones concretas y puntuales un medio para existir políticamente, de hacer algo para que la sociedad progrese. Es sobre todo en relación a la protección del medio ambiente que este modo de acción política ha empezado a desarrollarse. Por ejemplo, movimientos que han tenido lugar en Larzac ${ }^{66}$, intervenciones de Greenpeace contra la energía nuclear, ocupaciones de locales para reivindicar el derecho a la vivienda, contra el cierre de fábricas, las acciones de José Bové contra los OGM67 o la movilización de ATTAC por

\footnotetext{
65 NT: El 29 de mayo de 2005, el pueblo francés se pronunció acerca del proyecto de Constitución Europea a través del instrumento del referéndum con una participación del 69,37\%. De estos, 44,18\% se pronunciaron a favor de este proyecto y 53,30\% en contra. Los datos fueron tomados de: http://www.francepolitique.fr/referendum-2005.htm. Consultado el 08 de febrero 2013.

66 NT: Larzac es un altiplano dentro de la cordillera central de Francia (Massif Central), en 1971 el gobierno decide hacer un polígono de tiro militar produciendo un daño ambiental irreparable, los habitantes de este lugar muy poco poblado se negaron a vender sus tierras de vocación agrícola-ganadera al Ministerio de Defensa y emprendieron un sinfín de acciones para oponerse a la construcción de la base militar. Su lucha duro más de 10 años y es en Francia un ejemplo de resistencia civil por el medio ambiente, ya que gran parte de la sociedad civil apoyó a estos agricultores en la lucha por sus tierras. Para saber más acerca de este tema se puede consultar la página web: http://www.larzac.org/ consultada el 09 de febrero de 2013.

67 NT: José Bové es un personaje contradictorio, para unos un emblemático político defensor del medio ambiente, para otros un vándalo. Este individuo -agricultor de profesión- participó activamente de la lucha del Larzac y en contra la implementación de OGM en la agricultura. Fue enjuiciado y condenado por sus acciones en la lucha en contra de las semillas genéticamente modificadas en varias ocasiones: en 1995, 1997 y 1999 . Irrumpió con otros manifestantes en las instalaciones de varias empresas privadas dedicadas a este negocio (entre ellas Cirad y Novartis), en el año 2000 es condenado a 3 meses de prisión por haber participado en la destrucción de un McDonald's. Es delegado de la confederación campesina del 2004 al 2007; en el 2008 se presenta como candidato del partido ecologista y elegido en el parlamento europeo. Datos tomados de: http://www.jose-bove.eu/, consultado el 09 de febrero de 2013.
} 


\section{DERECHO ELECTORAL}

el impuesto Tobin ${ }^{68}$. Este fenómeno se desarrolla en numerosos países, particularmente en Japón para la protección del medio ambiente y de los consumidores, en los Estados Unidos, o en África para proyectos de desarrollo. ¿Será una regresión, una vuelta a las "Jaqueries"69, a luchas relacionadas exclusivamente con una revuelta aislada y carente de toda estructura política? Claramente no, o no exclusivamente. Se trata de medios muy eficaces para atar el lazo político; lejos de ser un simple cuestionamiento de las instituciones, constituyen medios de actuar fuera de los marcos existentes, pero para restablecer un diálogo con estos marcos, para compelerlos a comprometerse concretamente sobre problemas precisos. Además, estos movimientos conducen a crear, federar o reforzar las asociaciones que se forman alrededor de estos proyectos y frecuentemente son un primer paso hacia un mejor conocimiento del mundo político. Reúnen individuos "electrones libres", asociaciones, a veces sociedades privadas, entes descentralizados territorialmente, incluso representantes de la ONU. Este tipo de acción política no reemplaza la democracia representativa, tampoco la cuestiona, se trata más bien de un aguijón para estimular la acción de los representantes del pueblo.

Esta crisis está ligada a la evolución de nuestras instituciones y a la práctica del poder político. Demuestra que los ciudadanos han tomado conciencia del carácter ficticio de la representación política y parece indicar que una evolución de nuestras instituciones y su práctica sería necesaria. Si no se toman medidas para mejorar nuestra democracia, particularmente la participación de ciudadanos en las decisiones políticas y un control más fuerte de los representantes, es posible que esta crisis siga empeorando. En el estado actual de las cosas, puede esperarse que se trate simplemente de una especie de "crisis de adolescencia" de la democracia representativa, que llevará pronto a la madurez y a reforzar la democracia.

\footnotetext{
68 NT: ATTAC es una ONG fundada en 1998 para promover un impuesto a las transacciones financieras, esta organización propugna que los mercados financieros estén al servicio de los ciudadanos y no el contrario. Tiene filiales en más de 42 países. Tomado de la página web de la filial española: http://www.attac.es/, consultada el 09 de febrero 2013.

69 NT: Esta palabra es difícil de traducir. El diccionario Larousse Frances-Español de 1995 lo hace de la segunda manera: motín, pero inmediatamente agrega: "(...) levantamiento de campesinos (en recuerdo de una rebelión de los campesinos de la Isla de Francia contra la nobleza en 1358)". Cabe destacar que es usada de forma despectiva. Para ampliar: Noiriel, 2018, pp. 37-45 y Marseille, 2002, pp. 357-359.
} 


\section{DERECHO ELECTORAL}

\section{REFERENCIAS BIBLIOGRÁFICAS}

Beaud, O. (1987). À propos de C. Schmitt, Droits, (Número especial acerca de la representación).

Bodin, J. (1994). Los seis libros de la República. Madrid: Tecnos.

Cayla, O. y Thomas, Y. (2002). Du droit de ne pas naître. A propos de l'affaire Perruche. París, Francia: Gallimard.

Cohendet, M. (1993). La cohabitation. Leçons d'une expérience. París, Francia: Dalloz.

Cohendet, M. (2002a). Le président de la République. París, Francia: Dalloz.

Cohendet, M. (2002b). Droit constitutionnel. París, Francia: Montchrestien.

Dockés, E. (2004). Le pouvoir dans les rapports de travail: essor juridique d'une nuisance économiques. Droit Social, (6), 620-628.

Dockés, E. y Lhuillier, G. (2001). Le corps et ses représentations. París, Francia: LexisNexis.

Duguit, L. (2000). Leçons de droit public général faites en 1926. París, Francia: LGDJ.

Duhamel, O. (2002). Vers une VIº République?, Cités, (La France et ses démons).

Duhamel, O. y Mény, Y. (1992). Dictionnaire constitutionnel. París, Francia: PUF.

Dumont, G. (2002). La citoyenneté administrative (Tesis de doctorado). Universidad de Pantheon-Assas 2, París, Francia.

Gaxie, D. (1996). La démocratie représentative. París, Francia: Montchrestien.

Hamilton, A. (s.f.). El federalista. Recuperado de http://libertad.org/media/ElFederalista.pdf

Kelsen, H. (1988). La démocratie, sa nature, sa valeur. París, Francia: Económica.

L'Hôte, V. (2001). La responsabilité pénal des membres des exécutifs (Tesis de doctorado). Universidad de Nancy 2, Nancy, Francia

Robert, X. (2002). La Vie République? Revue du droit public et de la science politique en France et a l'etranger, (1-2), 1-572. 


\section{DERECHO EIECTORAL}

Tocqueville, A. (1981b). De la démocratie en Amérique, Vol. I, II parte, Cap. IX, París, Francia: Garnier-Flammarion.

Tocqueville, A. (1981a). De la démocratie en Amérique, Vol. II, II parte, Cap. IV. París, Francia: Garnier-Flammarion.

Troper, M. (1990). La justice constitutionnelle et démocratie. Revue française de droit constitutionnel, (1), 31-48.

\section{Referencias bibliográficas del traductor}

Alcubilla, E. (2019). El Funcionamiento del sistema electoral español. Revista de Derecho Electoral, (28), 177-183.

Alfaro, E. y Madriz, P. (2008). La reforma realizada en el año 2002 al artículo 195 de la Constitución Política: La posibilidad de someter a referéndum una reforma constitucional. Revista de Derecho Electoral, (5), 1-19.

Antillón, W. (2019). El Poder Judicial: crónica de una debacle. San José, Costa Rica: IJSA.

Carballo, A. (2016). ¿Derechos humanos sometidos a reférendum? Superando la regla de las mayorías desde la progresividad de los derechos humanos. Revista de Derecho Electoral, (21), 193-216.

Carro, L. (2017). Reformas a la Ley de Iniciativa Popular, porcentajes de firmas para la presentaciónd e proyectos. Revista de Derecho Electoral, (23), 217-233.

Cascante, M. (2016). Elecciones Municipales 2016: Datos para el análisis del sistema de partidos multinivel. Revista de Derecho Electoral, (22), 174-190.

Cascante, M. (2019). Preámbulo: la contribución de la política local a la democracia. Revista de Derecho Electoral, (28), 185-193.

Chacón, B. (2014). Cuestionamientos de la constitucionalidad del artículo 19 del Código Municipal, a la luz de la acción de inconstitucionalidad tramitada en el expediente n. ${ }^{\circ} 12-000255-0007-\mathrm{CO}$ de la Sala Constitucional. Revista de Derecho Electoral, (17), 226-269.

Cohendet, M. (2013). Droit constitutionnel. París, Francia: LGDJ.

Costa Rica. Tribunal Supremo de Elecciones (2018). Participación y abstencionismo: Serie histórica elecciones presidenciales 1982-2018. San José, Costa Rica: TSE. 


\section{DERECHO EIECTORAL}

Díaz, D. (2015). Crisis social y memorias en lucha. San José, Costa Rica: Editorial Universidad de Costa Rica.

Duverger, M. et al (2007). El referéndum (doctrina y legislación). San José, Costa Rica: Editorial Juricentro.

Esquivel, M.A. (2008). Referéndum en Costa Rica: La primera experiencia. Revista de Derecho Electoral, (6), 105-128.

Fernández, H. y Sánchez, I. (1999). Las consultas populares a nivel cantonal y distrital. San José, Costa Rica: IJSA.

Fernández, H. (2017). Justicia electoral y revocación de mandato de alcaldes e intendentes en Costa Rica. Revista de Derecho Electoral, (24), 105-128.

García, R. y González, J. (2008). Repaso histórico de los institutos de democracia semi directa en Costa Rica. Revista de Derecho Electoral, (5), 1-41.

Gaxie, D. (2006). La democracia representativa. Santiago, Chile: LOM Ediciones.

Gónzalez, D. (2018). Calidad de la relación entre representantes y representados en los sistemas proporcionales de elección de diputados. Revista de Derecho Electoral, (26), 29-43.

Gónzalez, R. (2017). Ley de Reférendum: Reflexiones a 10 años de su promulgación. Revista de Derecho Electoral, (23), 203-215.

Gómez, S. (2010). Mecanismos de democracia directa en América Latina: Una revisión comparada. Revista de Derecho Electoral, (10). 1-36.

Gordienko, A. (2015). La reforma política que Costa Rica necesita: La porpuesta de poder cuidadano iYa! Revista de Derecho Electoral, (20), 206-238.

Gordienko, A. (2019). Una reforma electoral para Costa Rica y su potencial de promover el desarrollo equitativo de todo el territorio nacional. Revista de Derecho Electoral, (27), 127-150.

Hernández, R. (2004a). El Derecho de la Constitución. San José, Costa Rica: Editorial Juricentro.

Hernández, R. (2004b). El Derecho electoral costarricense. San José, Costa Rica: Editorial Juricentro.

Lauvaux, P. (2004). Les grandes démocraties contemppraines. París, Francia: PUF.

Marseille, J. (2002). Nouvelle histoire de la France, vol.I. París, Francia: Perrin. 


\section{DERECHOEIECTORAL}

Matheus, D. (2008). La regulación del referendo revocatorio de madato en Venezuela y en Colombia. Revista de Derecho Electoral, (6), 1-24.

Montesquieu, C. (2005). El espíritu de las leyes. Bogotá, Colombia: Ediciones Universales.

Noiriel, G. (2018). Une histoire populaire de la France. Marsellas, Francia: Agone.

Raventós, C. et al (2005). Abstencionistas en Costa Rica: ¿Quiénes son y por qué no votan? San José, Costa Rica: Editorial Universidad de Costa Rica/ IIDH/ TSE.

Raventós, C. et al (2011). Respuestas ciudadanas ante el malestar con la política: Salida, voz y lealtad. San José, Costa Rica: Universidad de Costa Rica/TSE.

Rivera, J. (2006). Revocatoria del mandato para funcionarios de elección popular en los gobiernos locales. Revista de Derecho Electoral, (2), 1-42.

Robles, A. (2016). La reforma constitucional por la vía referendaria en Costa Rica. San José, Costa Rica: IFED-TSE.

Rosales, R. (2015). Problemas de la representación política y de los partidos en Costa Rica: Oportunidad para un diálogo social reconstitutivo. Revista de Derecho Electoral, (20), 239-275.

Rousseau, J. (2001). El contrato social. Trad. Doppelheim, Madrid, España: Mestas.

Shina, F. (2009). La libertad de expresión y otros derechos personalísimos. Buenos Aires, Argentina: Editorial Universidad.

Sobrado, L. (2007). Primera experiencia de reférendum en Costa Rica: Alcances y regulaciones. Revista de Derecho Electoral, (4), 1-19.

Sobrado, L. (2014). Elecciones y democracia. San José, Costa Rica: IFED-TSE.

Terré, F. y Fenouillet, D. (2011). Droit civil: La famille. París, Francia: Dalloz.

Trejos, S. (2014). El ideal democrático: la democracia direta. Revista de Derecho Electoral, (18), 131-149.

Trejos, S. (2017). Institutos de democracia direta: La iniciativa popular. Revista de Derecho Electoral, (23), 235-259.

Zaffaroni, E. (2005). En busca de las penas perdidas. Buenos Aires, Argentina: EDIAR. 


\section{DERECHO ELECTORAL}

Zaffaroni, E. (2013). La cuestión criminal. Bogotá, Colombia: Ibabañez.

Zaffaroni, E. (2017). La palabra de los muertos. Buenos Aires, Argentina: EDIAR.

Zamora, E. (2016). De 1813 a 2016: 202 años de elecciones municipales. Revista de Derecho Electoral, (21), 36-71.

Zovatto, D. (2015). Las instituciones de la democracia directa. Revista de Derecho Electoral, (20), 34-75. 